\title{
First Dendroclimatological Insight into Austrian Pine (Pinus nigra Arnold) Climate-Growth Relationship in Belgrade Area, Serbia
}

\author{
Branko Stajić ${ }^{1 *}$, Marko Kazimirović ${ }^{1}$, Vojislav Dukić ${ }^{2}$, Nenad Radaković ${ }^{3}$
}

(1) University of Belgrade, Faculty of Forestry, Department of Forest Management Planning, Kneza Višeslava 1, RS-11030 Belgrade, Serbia; (2) University of Banja Luka, Faculty of Forestry, Department of Forest Management Planning, Bulevar Vojvode Stepe Stepanovića 75A, BA-78000 Banja Luka, Bosnia and Herzegovina; (3) Public Enterprise "Djerdap National Park", Kralja Petra I broj 14a, RS-19220 Donji Milanovac, Serbia

* Correspondence: e-mail: branko.stajic@sfb.bg.ac.rs
Citation: Stajić B, Kazimirović M, Dukić V, Radaković N, 2020. First Dendroclimatological Insight into Austrian Pine (Pinus nigra Arnold) Climate-Growth Relationship in Belgrade Area, Serbia. South-east Eur for 11(2): early view. https://doi.org/10.15177/seefor.20-12. Received: 1 Jul 2020; Revised: 22 Sep 2020; Accepted: 23 Sep 2020; Published online: 8 Oct 2020

\begin{abstract}
In order to assess the impact of climate variations on Austrian pine forest in the Belgrade area, the radial growth of artificially-established Austrian pine trees and its dependence on temperature and precipitation was studied using dendroclimatological methods. The site is classified as Quercetum-frainetto cerris Rudski. Standard and residual chronologies were established and several common statistics were calculated. A dendroclimatic study was carried out using the correlation and response function analysis. The Pearson correlation coefficients between the chronology indices and 13 seasonal (3-month period) precipitation and temperature data were calculated for the period from 1959 to 2014 . The applied response function analysis included 24 precipitation and temperature variables from October of the prior year to September of the current year. The results of the correlation analysis pointed out that there was a strong tendency towards a positive response to the summer and late summer/early autumn precipitation and a weak significant negative response to the spring and summer temperatures. Climate-growth relationships were further first studied using the response functions for the significant seasons that were detected from the correlation analysis and then for individual months from previous October to current September. These results also highlighted the findings that higher precipitation in the current summer months has a beneficial effect on the tree-ring width. The conducted correlation between the residual chronology and the Standardised Precipitation Evapotranspiration Index indicated that a high summer value of this drought index had a positive impact on the pine growth and reinforced the previously detected relevance of September as an important month for the Austrian pine growth. These preliminary results point out that some additional climate-Austrian pine growth studies (application of various tree-ring features, growth data with a much longer time span, more sites/stands, etc.) should be performed to obtain new and valuable knowledge important for the sustainable management of Austrian pine forests.
\end{abstract}

Keywords: radial growth; dendroclimatology; sessile oak; temperature and precipitation; Serbia

\section{INTRODUCTION}

Climate change in Central Europe (temperature rise and, above all, the increasing drought risk) is forcing forestry in Central Europe to make forests resilient to future climate conditions (Walentowski et al. 2017). Similar future climate projection could be noted for the South-Eastern Europe region (Angelini et al. 2012), causing climate variations which could generally affect many aspects of forest ecosystems, including tree growth and dieback, insect outbreaks, species distributions, and the seasonality of ecosystem processes (Seppälä et al. 2009).

For this reason, the growth of trees as the main component of forest ecosystems could be one of the most useful (bio)indicators, reflecting the general health and sustainability of forests and providing comprehensive knowledge of long tree and forest history needed for the understanding of forest dynamics and past environmental changes (Fritts 1976, Richter et al. 1991, Spiecker 2002, Juknys et al. 2002, Leal et al. 2008, Stajić et al. 2015). Due to 
a number of its specificities (precision of measurements, close relationship with climatic and other environmental factors, ability to collect data for several centuries back, etc.), research of radial tree growth is of particular importance in the analysis and definition of the "nature" of tree and forest responses to changes in the basic growth conditions, including those related to climate (Stajic 2014). In that context, radial tree growth chronologies are high-resolution proxy sources used to reconstruct climatic variation at longer time scales (Esper and Gärtner 2001). Additionally, in their annual rings, trees preserve an archive of past growing conditions reflecting competition, disturbance, soil characteristics or species-specific growth patterns, as well as human-induced disturbances (Ostrogović Sever et al. 2017).

Such investigations of the dependence of radial growth on the climate and other factors are of particular importance for Serbia's Austrian pine forests. First, its high wood quality, wide range of utility values, ability to adapt to nutritive conditions of unfavourable substrates, resistance to harmful chemical agents ( $\mathrm{SO}_{2}$ etc.) and capability to grow and produce wood in fairly modest site conditions make Austrian pine capable of fulfilling complex forest functions starting from the economic over ecological and protective to aesthetic functions (Vučković et al. 2010). Second, Austrian pine is one of the most significant tree species used for afforestation on dry sites in South-Eastern Europe (Ivetić, Škorić 2013). Additionaly, the present condition of artificiallyestablished stands of Austrian pine as the dominant species for afforestation in Serbia is due to insufficient and inadequate silvicultural measures particularly unfavourable in terms of health, vitality and use of production potential.

According to Stojanović et al. (2014), Austrian pine is one of the tree species in Serbia which is not under considerable risk due to climate change. This evaluation was performed using forest aridity index. However, the impact of climate change on forests can be more comprehensively assessed by studying climate-tree radial growth variation in a multiannual period, i.e. by dendroclimatological research. Besides oaks, pines are probably the most investigated tree species from the aspect of dendroclimatology in Europe (Lebourgeois 2000, Läänelaid and Eckstein 2003, Leal et al. 2008, Hordo et al. 2009, Popa and Kern 2009, Poljanšek et al. 2013, Mazza et al. 2014, Smiljanić et al. 2014, Levanič et al. 2015, Bojaxhi and Toromani 2017, Kalbarczyk et al. 2018). It is evident that pines show different growth-climate relationships depending on species, location and climate conditions (Akkemik 2000, Miina 2000, Nöjd and Hari 2001, Panayotov and Yurukov 2007, Mazza et al. 2014, Levanič et al. 2015, Stajić and Kazimirović 2018, etc.).

Modern dendroclimatological procedures have not been often applied to study climate data recorded for Austrian pine radial growth in Serbia. The only research of this type in Serbia was carried out by Stajić and Kazimirović (2018). The results showed that Austrian pine in the area of Rudnik Mountain was very sensitive to precipitation in summer months in the given conditions, in the way that higher amounts of summer precipitation resulted in significantly higher radial increment values. In this sense, the objective of this research was to assess the radial growth of Austrian pine and its dependence on temperature and precipitation in an artificially-established stand in Belgrade area.

\section{MATERIAL AND METHODS}

The trees were cored in a 60-year-old, artificiallyestablished stand of Austrian pine nearby Belgrade. The investigated site is located at approximately $300 \mathrm{~m}$ a.s.l. and it is classified as Quercetum-frainetto cerris. The soil depth on a moderate terrain slope $\left(10^{\circ}\right)$ is $20-40 \mathrm{~cm}$. According to Vučković et al. (2008), the site belongs to yield class II. Climate data were obtained from the nearest meteorological station "Belgrade-Vracar", situated at a similar elevation. The climate is humid continental with an average daytime temperature of $12.3^{\circ} \mathrm{C}$ and the average annual precipitation of $692.4 \mathrm{~mm}$.

Two cores were taken at breast height at opposite sides of the trunk from each of the 24 selected trees (48 radial increment series). The sample was cross-dated visually, using TSAP and R (R Core Team, 2008). The library dpIR (Bunn et al. 2008) was used to evaluate the measurements and the overall quality of the sampled radial increment series. The radial growth series were standardized with a cubic smoothing spline having a $50 \%$ cut-off of 32 years (Cook and Peters 1981). Radial increment indices were computed by dividing each radial growth value by the value of the fitted curve of that year. The detrended series were averaged to obtain the standard (STD) master chronology by applying a biweight robust estimation of the mean value function (Cook et al. 1990). In order to construct residual site chronology (RES), the detrended series were prewhitened with autoregressive models whose order was determined according to Akaike Information Criterion (AIC). The quality of the chronologies was evaluated by Mean Sensitivity (MS) (Fritts 1976), Expressed Population Signal (EPS) (Fritts 1976, Wigley et al. 1984), Signal-to-Noise Ratio (SNR) (Wigley et al. 1984) and the first Principal Component (PC1) (Fritts 1976). Temporal stability of EPS was investigated by the annual moving of 30-year long timeframes across chronologies.

In order to detect the pattern of Austrian pine growthclimate relationships in the study area, correlation and response functions between radial increment indices and climate data were conducted by using Treeclim library (Zang and Biondi 2015). The correlation analysis was primarily applied to seasonal 3-month data, where the response function was calculated for the significant seasons from the correlation analysis, and then to monthly data, for a sequence of 24 months starting from October of the previous year to September of the current growing season. The stability of the obtained coefficients through time for 21 monthly calibrations of the response function was determined by using a 30-year moving window. Finally, we calculated the Standardized Precipitation-Evaporation Index (SPEI) (Begueria and Vicente-Serrano 2014) and correlated it with radial increment indices for the same months as in the response function. To quantify drought through SPEI index, the potential evapotranspiration was computed according to the Hargreaves equations. 


\section{RESULTS}

\section{Quality Indicators of Radial Increment Chronologies}

The most important characteristics of radial increment series (row data) are as follows: the average level of correlation coefficient $\left(r_{x y}\right)$ and t-test value $\left(t_{b p}\right)$ of each normalized series with the master chronology (Baillie and Pilcher 1973), the average values of mean sensitivity (MS) and the first order autocorrelation coefficients (AC1) are $0.75,4.75,0.30$ and 0.80 , respectively.

In order to quantify the common and different features of both chronology versions in the representation of the climatic potential of growth data, statistical characteristics of STD and RES master chronologies were calculated for the common period of all series, from 1959 to 2014 (Table 1). The obtained chronologies are 56 and 55 years long site STD and RES chronologies with the average time span of a series amounting to 51 years. The percentage of the variance explained by PC1 for both types of chronology is similar (49.78\% and $52.96 \%)$. According to the values of EPS from the moving window, both versions of the chronologies have sufficiently strong common signal in their entire lengths. However, the values of the applied statistics are more favourable for RES than STD. Therefore, RES chronology was selected to evaluate the effects of climate variations on Austrian pine radial growth in this study.

\section{Radial Growth-Climate Relationships}

The obtained Pearson's correlation coefficients between RES chronology indices and the seasonal (3-month) and monthly climate parameters are shown in Figure 1a and Figure $1 b$, respectively. Starting from the current November as the expected end of the growing period to October of the previous year, 13 different seasons of the same length (3 months) were first analyzed. The most pronounced growthclimate relationships were detected for the precipitation in the period between June and August $(r=0.603)$ of the current growing season, while the temperature had a less expressed but significantly negative correlation over the periods of April-June ( $r=-0.335)$ and June-August ( $r=-0.293)$. At a monthly scale, Austrian pine growth was positively correlated with current June, July and August precipitation, while significant negative relationships were recorded between radial growth indices and temperature during April and August.

To determine the combined effect of precipitation and temperature, the response function was calculated for the three most expressed 3-month seasons obtained by the conducted correlation analysis (April-June, May-July and June-August). This procedure revealed only the existence of a significant positive correlation between radial growth indices and precipitation in the current June-August, while the other seasons were insignificantly related (Figure 2a). Besides, the calculation of the response function over the sequence of 24 months pointed to a positive relation with June and July precipitation of the current year (Figure $2 b)$. The applied procedure did not detect any significant negative effects of temperature, but the positive impact on radial increment indices was recognized for September of the current year.

Table 1. Statistical characteristics of standard (STD) and residual (RES) site chronologies for the longest common period of all series (1969-2014).

\begin{tabular}{cccccccccc}
\hline Chronology & $r_{\text {tot }}$ & $r_{\text {wt }}$ & $r_{b t}$ & SD & EPS & SNR & MS & AC1 & PC1 \\
STD & 0.476 & 0.678 & 0.472 & 0.214 & 0.969 & 30.851 & 0.220 & 0.112 & 49.78 \\
RES & 0.501 & 0.649 & 0.497 & 0.207 & 0.973 & 36.172 & 0.234 & -0.079 & 52.96 \\
\hline
\end{tabular}

a)

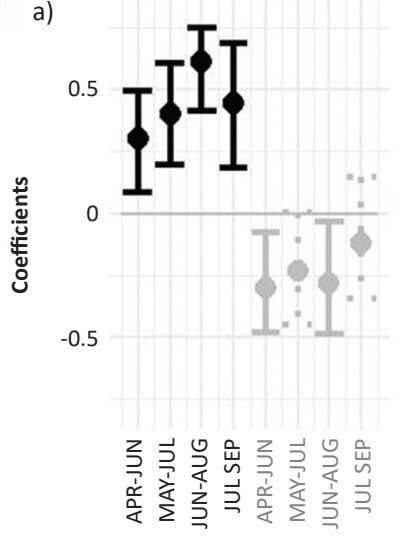

b)

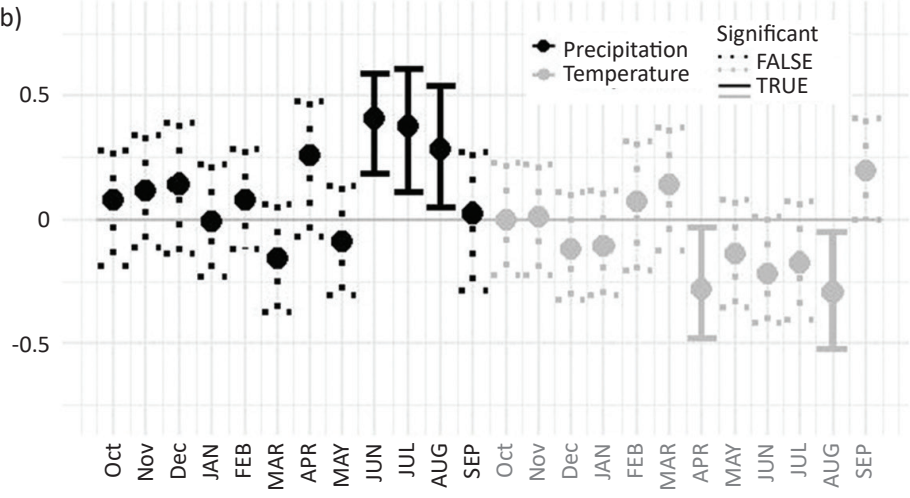

Figure 1. The correlation between the seasonal (a) and monthly (b) climate parameters and growth indices of residual site (RES) chronology. The darker bars indicate coefficients which are significant at a $0.05 \alpha$-level (two-tailed test). 

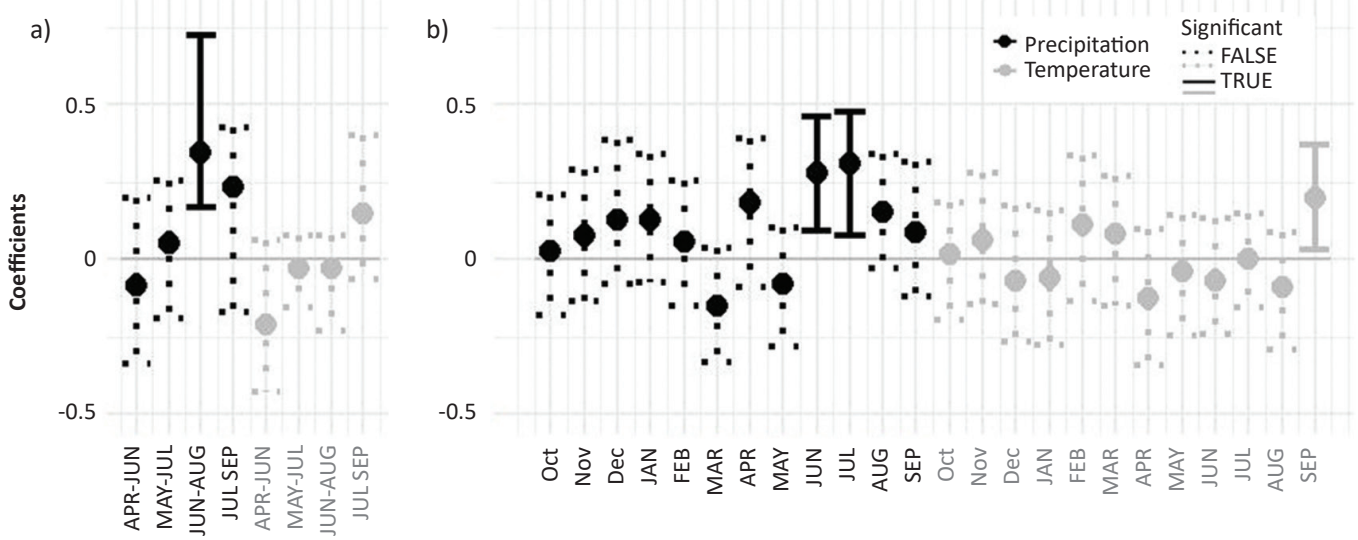

Figure 2. The bootstrapped values of the response function coefficients for the precipitation and temperature 3-month seasons (a) and monthly data (b), starting from October of the previous year to September of the current year. Uppercase and lowercase denotes the month of the current growing seasons and the month in the previous year, respectively (b).

In addition, the coefficients of the determined climategrowth relationships were tested for stability through the investigated time sequence (Figure 3). The 30-year long moving windows revealed the existence of divergent response to prevailing climate conditions. Seven of the first nine moving windows indicate that higher temperatures in September could positively affect radial growth due to the prolonged growing season. Afterwards, the significant influence of this parameter disappears. This occurrence coincides with the warming trends observed for September temperatures. Since 1997, the mean temperature during September increased by exactly 2 degrees in comparison to the previous period. Besides, the last 20 positions of the moving windows confirmed the importance of precipitation during the summer (Figure 3, bottom part). However, apart from the quite significant and consistent influence of July rainfalls, it seems that June precipitation is not that important as it seems from the monthly correlation and response analysis data. Instead, it has been determined that the amount of August precipitation has a substantial role in radial growth of Austrian pine on this site.

Furthermore, RES chronology indices were correlated with SPEI for the same months as in the response function. The determined coefficients pointed to significant relations for July ( $r=0.297)$ and August ( $r=0.228$ ) of the current year (Figure 4b). Following the previously observed seasonal influences, it was detected that a significant correlation between SPEI and radial increment indices existed only for the June-August period (Figure 4a).

\section{DISCUSSION}

\section{Assessment of the Radial Increment Chronologies}

The evaluation of the analyzed samples was tested by using a variety of dendrochronological and statistical parameters. The high inter-series correlation $(0.75)$ pointed to quite similar reactions of the analyzed trees to the factors influencing Austrian pine growth. The extremely high average value of the first order autocorrelation coefficient -
AC1 $(0.80)$ indicated a high level of influence of the previous year's growth factors on the radial increment values of the current year. This value is larger than AC1 value of 0.77 recorded for Austrian pine trees in south-western Romania (Levanič et al. 2013), same as the results of Levanič and Toromani (2010) for Austrian pine in north-eastern Albania (0.80), and smaller than the average AC1 value (0.85) for Austrian pine row radial increment series in south-western Bulgaria (Shishkova and Panayotov 2013a).

For RES chronology, the values of MS (0.23), EPS (0.98) and SNR (36.2) are high, especially EPS and SNR. The implemented procedures (standardization, averaging the obtained indices and performing the autoregressive modelling) removed the low-frequency trend and autocorrelation from the raw tree-ring data. According to the obtained results, it is obvious that RES chronology contains the desired common signal which represents the common variability present in all series of radial increment indices, so this version of chronology could be useful for further analysis of growth-climate relationships.

\section{Response to Climate Variables}

Previous studies of Austrian pine from different parts of Europe outlined the species as valuable for dendroclimatic analyses (Strumia 1997, Lebourgeois 2000, Shishkova and Panayotov 2013). However, the growth-climate relationships are highly dependent on the nature of the investigated area (altitude, site, etc.), as well as on the climate type. Austrian pine trees used in this research originate from a managed forest and grow in a temperate region in less extreme site conditions, i.e. with various factors influencing its radial growth. Therefore, the identification of the proper growthclimate relationship in such site and stand conditions can often be a serious problem (Vučković et al. 2005). Bearing this in mind, the influence of climatic factors on the radial increment of Austrian pine trees in our study was studied by means of (1) the correlation analysis between radial increment indices and seasonal and monthly climate/SPEI data and (2) the response function analysis. 

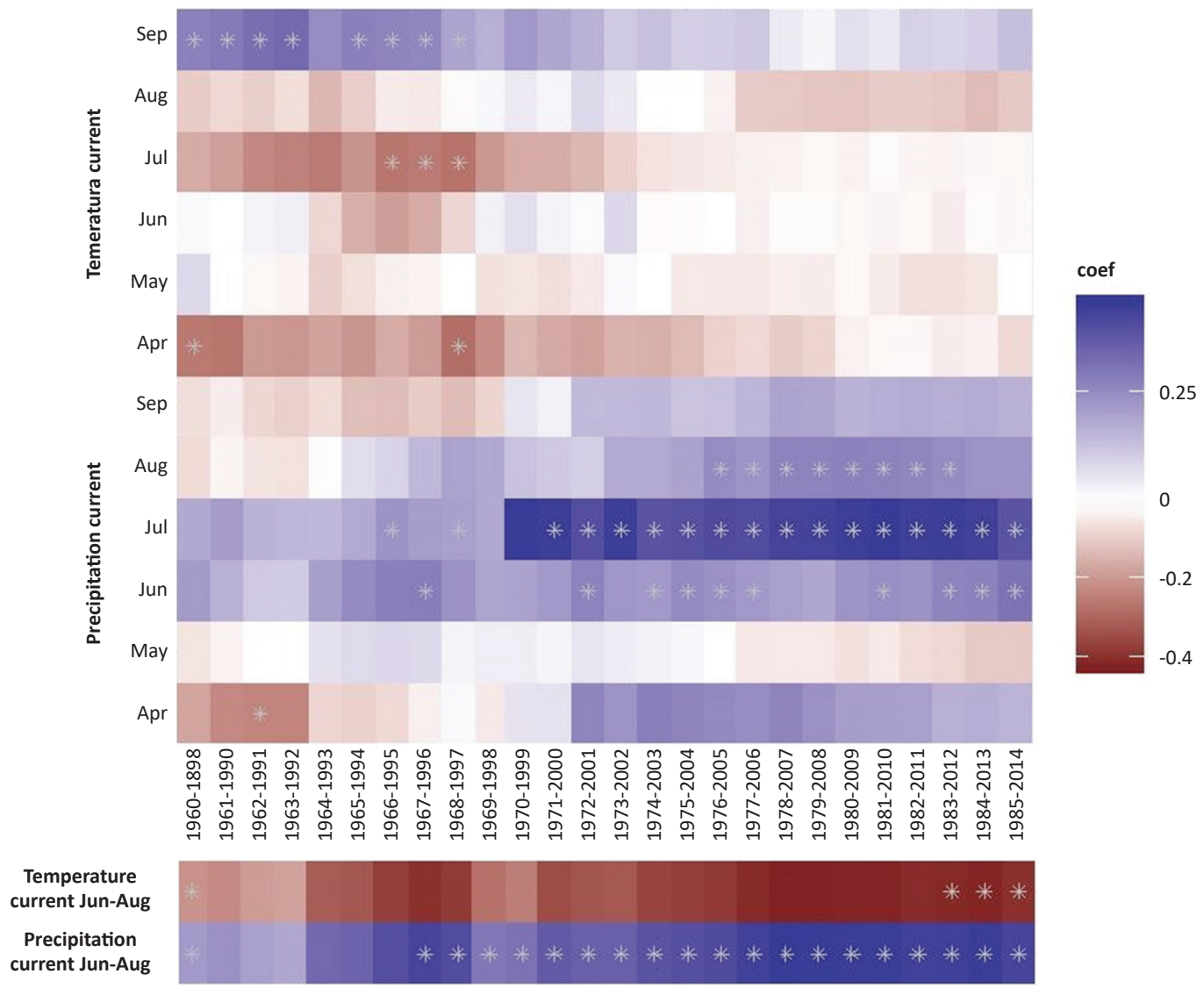

Figure 3. The temporal stability of response function, determined by a 30-year moving window. The stars designate the significant response coefficients.

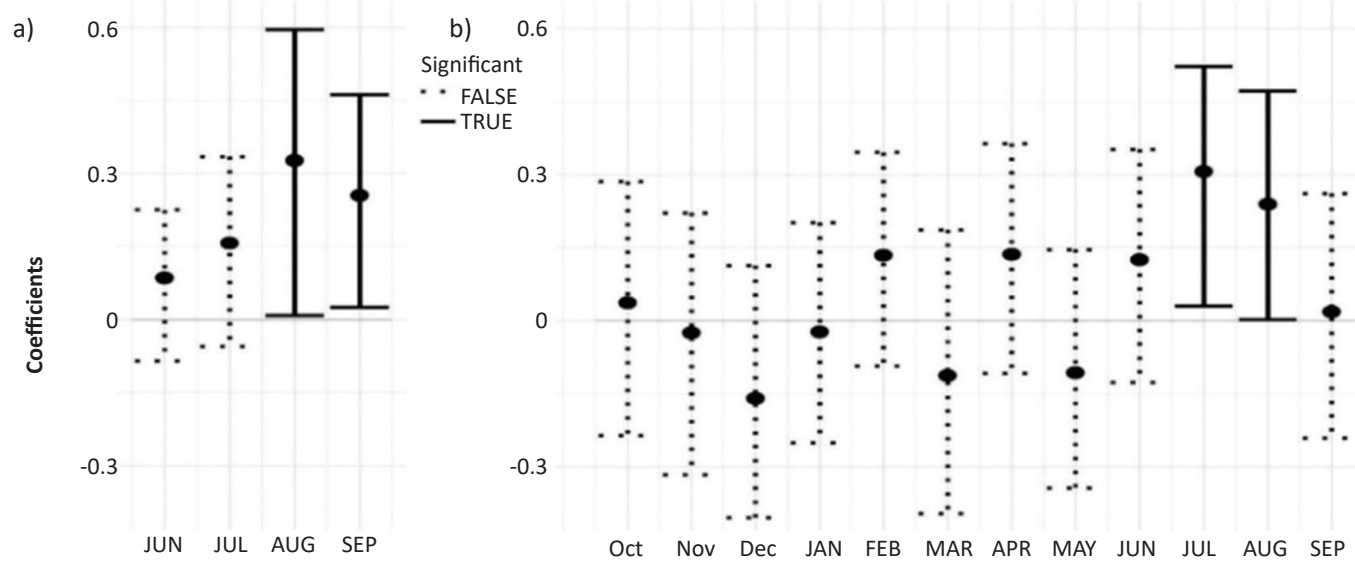

Figure 4. The bootstrapped values of the correlation coefficients between residual site chronology (RES) and Standardized Precipitation-Evaporation Index (SPEI) 3-month seasons (a) and monthly data (b). 
According to the results of the correlations between radial increment indices and 3-month climate data, it can be concluded that high spring and summer precipitation of the current year result in a larger pine radial increment. This procedure also points to a reduction in the pine radial increment with the increase of temperature in the current spring and summer. The results of the response function analysis for the most pronounced 3-month periods have highlighted the prevailing effect of the current summer precipitation on the values of the radial increment. Apart from that, the calculation of the response function for the sequence of 24 months confirmed that higher precipitation in the current summer months has a beneficial effect on tree-ring width. The conducted response function analyses (seasonal and monthly data) did not detect any negative influence of temperature, although a positive effect on the radial increment indices was recognized for September of the current year.

The determined dependence of the Austrian pine growth on summer precipitation corresponds to some results of earlier research studies from South-East Europe (SEE) region. In that context, there are positive correlations between summer precipitation and the growth of Austrian pine in Bosnia and Herzegovina (Poljanšek et al. 2013) and in south-western Bulgaria (Shishkova and Panayotov 2013a). A positive correlation between $P$. nigra radial growth and precipitation was also found for the summer months of the current year in south-western Bulgaria (Shiskova and Panayotov 2013a) and particularly for July in the south of Bulgaria (Shishkova and Panayotov 2013b). Levanič et al. (2013) identified July precipitation as the most important factor influencing $P$. nigra growth in a natural stand in Romania. A significant positive pine growth response to July precipitation was detected in Albania, but it was weaker than July temperature (Levanič et al. 2015). In addition, the utmost importance of the precipitation from the previous year for the formation of the radial $P$. nigra growth of the current year was not recorded here, although some results from SEE region (Shishkova and Panayotov 2013b) indicate that these monthly or seasonal precipitations could have important positive effects on $P$. nigra radial growth values.

Our study reveals a less pronounced impact of temperature on the values of the Austrian pine radial increment. This less expressed temperature signal is "stretched" over months from April to September. For this reason, and having in mind that an application of drought indices can often provide a better insight into the tree's response than temperature/precipitation data alone (Levanič et al. 2013, Lévesque 2013), we additionally determined SPEI drought index and correlated it with $P$. nigra radial growth indices. According to Ma et al. (2015), this information can broaden our knowledge regarding the vulnerability of trees to climate change and our ability to predict future drought variations. Namely, the interaction between temperature and precipitation, which was summarized in SPEI, caused tree growth (either the width or the anatomical variables) to show the highest correlations with SPEI (Martin-Benito et al. 2012). The obtained results confirmed the aforementioned statement that the highest correlation $(r=0.60)$ between $P$. nigra growth and the applied climate variables was detected with 3-month August SPEI. According to this result, a high summer SPEI had a positive impact on an increase of $P$. nigra radial increment values. This correlation coefficient of JuneAugust SPEI is more than twice as important for the increase of pine radial increment as June-August temperature. In addition, the determined positive relationship between 3-month September SPEI and RES chronology reinforced the relevance of September as an important month for the Austrian pine radial growth, previously detected by the results of the applied response function for the mean temperature monthly data (Figure 2). Finally, since the effect of temperature on radial growth is generally opposite to that of precipitation, the results of SPEI application partly pointed to the importance of temperature for $P$. nigra in the area of Belgrade.

\section{CONCLUSIONS}

Based on the results of this study, we could preliminary assume that the relationship between Austrian pine radial increment and climate data shows a tendency towards a positive response to summer precipitation and a weak negative response to summer and early autumn temperature. In that context, the first obtained results indicate that summer drought seems to be partially important for the radial growth of this species. Additionally, these preliminary results point out that more complex climate-Austrian pine growth studies (application of various tree-ring features, growth data with a much longer time span, more sites/ stands, etc.) should be performed to obtain new valuable knowledge important for the sustainable management of Austrian pine forests. Such data are of highest concern both from the perspective of management and science (Bhuyan et al. 2017).

\section{Author Contributions}

BS and MK conceived and designed the research, MK and NR performed the field measurements, MK and NR performed laboratory analysis, BS and MK processed the data and performed the statistical analysis, BS, MK and VD wrote the manuscript, VD did the final checking and proofreading of the manuscript text.

\section{Funding}

This paper was realized as a part of the Project financed by the Ministry of Education and Science of the Republic of Serbia (451-02$68 / 2020 / 14 / 2000169$ from 24.01.2020).

\section{Conflicts of Interest}

The authors declare no conflict of interest.

\section{Acknowledgement}

This paper was realized as a part of the Project financed by the Ministry of Education and Science of the Republic of Serbia (451-0268/2020/14/2000169 from 24.01.2020). 


\section{REFERENCES}

Akkemik U, Aras A, 2005. Reconstruction (1689-1994 AD) of April-August precipitation in the southern part of Central Turkey. Int J Climatol 25(4): 537-548. https://doi.org/10.1002/ joc.1145.

Baillie MGL, Pilcher JR, 1973. A simple cross-dating program for tree-ring research. Tree Ring Bulletin 33: 7-14.

Beguería S, Vicente-Serrano SM, Reig F, Latorre B, 2014. Standardized precipitation evapotranspiration index (SPEI) revisited: parameter fitting, evapotranspiration models, tools, datasets and drought monitoring. Int J Climatol 34(10): 30013023. https://doi.org/10.1002/joc.3887.

Bhuyan U, Zang C, Menzel A, 2017. Different responses of multispecies tree ring growth to various drought indices across Europe. Dendrochronologia 44: 1-8. https://doi. org/10.1016/i.dendro.2017.02.002.

Bunn AG, 2008. A dendrochronology program library in $R$ (dplR). Dendrochronologia 26(2): 115-124. https://doi. org/10.1016/i.dendro.2008.01.002.

Cook E, Peters K, 1981. The smoothing spline: A new approach to standardizing forest interior tree-ring width series for dendroclimatic studies. Tree Ring Bulletin 41: 45-53.

Cook ER, Briffa K, Shiyatov S, Mazepa V, 1990. Tree-Ring Standardization and Growth Trend Estimation. In: Cook ER, Kairiukstis LA (eds) Methods of dendrochronology: applications in the environmental sciences. Kluwer academic publishers, Dordrecht, Boston, London, pp 104-162.

DeWeese GG, Grissino-Mayer HD, Lafon CW, Aldrich SR, 2010. Evaluating the dendroclimatological potential of central Appalachian Table Mountain pine (Pinus pungens LAMB.). Dendrochronologia 28(3): 173-186. https://doi.org/10.1016/i. dendro.2009.10.001.

Esper J, Gärtner H, 2001. Interpretation of tree-ring chronologies. Erdkunde 55: 277-287.

Fritts HC, 1976. Tree Rings and Climate. Academic Press, London, UK, $567 \mathrm{p}$.

Hordo M, Metslaid S, Kiviste A, 2009. Response of Scots Pine (Pinus sylvestris L.) Radial Growth to Climate Factors in Estonia. Balt For 15(2): 195-205.

Ivetić V, Škorić M, 2013. The impact of seeds provenance and nursery production method on Austrian pine (Pinus nigra Arn.) seedlings quality. Ann For Res 56(2): 297-305.

Juknys R, Stravinskiene V, Vencloviene J, 2002. Tree-ring analysis for the assessment of anthropogenic changes and trends. Environ Monit Assess 77: 81-97. https://doi. org/10.1023/A:1015718519559.

Läänelaid A, Eckstein D, 2003. Development of a tree-ring chronology of Scots pine (Pinus sylvestris L.) for Estonia as a dating tool and climatic proxy. Balt For 9 (2): 76-82.

Leal S, Eamus D, Grabner M, Wimmer R, Cherubini P, 2008. Tree rings of Pinus nigra from the Vienna basin region (Austria) show evidence of change in climatic sensitivity in the late 20th century. Can J Forest Res 38(4): 744-759. https://doi. org/10.1139/X07-189.

Lebourgeois F, 2000. Climatic signals in earlywood, latewood and total ring width of Corsican pine from western France. Ann Forest Sci 57(2): 155-164. https://doi.org/10.1051/ forest:2000166.

Levanič T, Toromani E, 2010. Austrian pine (Pinus nigra Arnold.) tree-ring width chronology from northeast Albania preliminary results. In: Levanič T, Gričar J, Hafner P et al. (eds) Proceedings of the Dendrosymposium: TRACE - Tree Rings in Archaeology, Climatology and Ecology. Otočec, Slovenia, 16-19 April 2009. Deutsches GeoForschungsZentrum GFZ, Potsdam, Germany, pp 104-109.
Levanič T, Popa I, Poljanšek S, 2013. A 323-year long reconstruction of drought for SW Romania based on black pine (Pinus nigra) tree-ring widths. Int J Biometeorol 57: 703714. https://doi.org/10.1007/s00484-012-0596-9.

Levanič T, Poljanšek S, Toromani E, 2015. Early summer temperatures reconstructed from black pine (Pinus nigra Arnold) tree-ring widths from Albania. The Holocene 25(3): 469-481. https://doi.org/10.1139/X07-189.

Ma Y, Liu Y, Song H, Sun J, Lei Y, Wang Y, 2015. A Standardized Precipitation Evapotranspiration Index Reconstruction in the Taihe Mountains Using Tree-Ring Widths for the Last 283 Years. PLOS One 10(7): 1-15. https://doi.org/10.1371/journal. pone. 0133605 .

Martin-Benito D, Beeckman H, Cañellas I, 2012. Influence of drought on tree rings and tracheid features of Pinus nigra and Pinus sy/vestris in a mesic Mediterranean forest. Eur J Forest Res 132: 33-45. https://doi.org/10.1007/s10342-012-0652-3.

Mazza G, Cutini A, Manetti MC, 2014. Site-specific growth responses to climate drivers of Pinus pinea $\mathrm{L}$. tree rings in Italian coastal stands. Ann Forest Sci 71: 927-936. https://doi. org/10.1007/s13595-014-0391-3.

Miina J, 2000. Dependence of tree-ring, earlywood and latewood indices of Scots pine and Norway spruce on climatic factors in eastern Finland. Ecol Modell 132(3): 259-273. https://doi. org/10.1016/S0304-3800(00)00296-9.

Nöjd P, Hari P, 2001. The effect of temperature on the radial growth of Scots pine in northernmost Fennoscandia. For Ecol Manage 142(1-3): 65-77. https://doi.org/10.1016/ S0378-1127(00)00340-6.

Ostrogović Sever MZ, Paladinić E, Barcza Z, Hidy D, Kern A, Anić M, Marjanović H, 2017. Biogeochemical Modelling vs. Tree-Ring Measurements - Comparison of Growth Dynamic Estimates at Two Distinct Oak Forests in Croatia. South-east Eur for 8(2): 71-84. https://doi.org/10.15177/seefor.17-17.

Panayotov MP, Yurukov S, 2007. Tree ring chronology from Pinus peuce in Pirin Mts and the possibilities to use it for climate analysis. Phytologia Balcanica 13(3): 313-320.

Piraino S, Camiz S, Di Filippo A, Piovesan D, Spada F, 2013. A dendrochronological analysis of Pinus pinea $\mathrm{L}$. on the Italian Mid-Tyrrhenian coast. Geochronometria 40(1): 77-89. https:// doi.org/10.2478/s13386-012-0019-z.

Poljanšek S, Ceglar A, Levanič T, 2013. Long-term summer sunshine/moisture stress reconstruction from tree-ring widths from Bosnia and Herzegovina. Clim Past 9(1): 27-40. https://doi.org/10.5194/cp-9-27-2013.

Popa I, Kern Z, 2009. Long-term summer temperature reconstruction inferred from tree-ring records from the Eastern Carpathians. Clim Dynam 32: 1107-1117. https://doi. org/10.1007/s00382-008-0439-x.

R Development Core Team, 2008. R: A language and environment for statistical computing. $R$ Foundation for Statistical Computing, Vienna, Austria. http://cran.r-project.org/.

Richter K, Eckstein D, Holmes RL, 1991. The dendrochronological signal of pine trees (Pinus spp.) in Spain. Tree-Ring Bulletin 51: 1-13.

Shishkova V, Panayotov M, 2013a. Pinus nigra Arn. Tree ring Chronology from Slavyanka Mts in Bulgaria is strongly related to regional drought events. Forestry Ideas 19(1)(45): 79-90.

Shishkova V, Panayotov M, 2013b. Climate-growth relationship of Pinus nigra tree-ring width chronology from the Rhodope Mountains, Bulgaria. Bulg J Agric Sci 19(2): 225-228.

Smiljanić M, Seo J-W, Läänelaid A, Van der Maaten-Theunissen M, Stajić B, Wilmking M, 2015. Peatland pines as a proxy for water table fluctuations: Disentangling tree growth, hydrology and possible human influence. Sci Total Environ 500-501: 5263. https:// doi.org/10.1016/i.scitotenv.2014.08.056. 
Stajić B, Vučković M, Janjatović Ž, 2015. Preliminary dendroclimatological analysis of Sessile oak (Quercus petraea (Matt.) Liebl.) in "Fruška Gora" National park, Serbia. Balt For 21(1): 83-95.

Stajić B, 2014. Pointer years in the growth of beech trees of the NP "Đerdap" area. Bulletin of the Faculty of Forestry 110: 175188. https://doi.org/10.2298/GSF1410175S.

Stajić B, Kazimirović $\mathrm{M}, 2018$. The influence of temperature and precipitation on the increment of Black pine (Pinus nigra J. F. Arnold): a case study from the area of Mt. Rudnik. Bulletin of Faculty of Forestry Belgrade 118: 143-164. https://doi. org/10.2298/GSF1818143S.

Strumia G, Wimmer R, Grabner M, 1997. Dendroclimatic sensitivity of Pinus nigra Arnold in Austria. Dendrochronologia 15: 129-137.

Vučković M, Stajić B, Smiljanić M, 2008. Elements of structure and growth of Austrian pine stand at the site of Turkish oak and Hungarian oak. Forestry (Belgrade) 60(4): 31-41. (in Serbian).
Vučković M, Stajić B, Smiljanić M, 2010. Ecological aspect of wood production and $\mathrm{CO} 2$ absorption in Austrian pine plantations in Serbia. In: Rakonjac LJ (ed) Proceedings of International Scientific Conference Forest Ecosystems and Climate Changes, Volume 2, Belgrade, Serbia, 9-10 March 2010, pp 171-177.

Walentowski H, Falk W, Mette T, Kunz J, Bräuning A, Meinardus C, Zang Ch, Sutcliffe L, Leuschner Ch, 2017. Assessing future suitability of tree species under climate change by multiple methods: a case study in southern Germany. Ann For Res 60(1): 101-126. https://doi.org/10.15287/afr.2016.789.

Wigley TML, Briffa KR, Jones PD, 1984. On the Average Value of Correlated Time Series, with Applications in Dendroclimatology and Hydrometeorology. J Climate App/ Meteor 23(2): 201-213. https://doi.org/10.1175/1520-0450(1984)023<0201:OTAVOC $>2.0 . \mathrm{CO} ; 2$.

Zang C, Biondi F, 2015. Treeclim: an R package for the numerical calibration of proxy-climate relationships. Ecography 38(4): 431-436. https://doi.org/10.1111/ecog.01335. 